\title{
The Dilemma and solution of Water pollution Control from the Perspective of Environmental Regulation
}

\author{
Chu Yijing ${ }^{1}$, Wang Jue ${ }^{2}$ \\ Wuhan Technical College of Communications, Economic Management Academy
}

\begin{abstract}
With the development of the economy in China, water pollution problems have become increasingly prominent and have received extensive attention in academic circles. At present, the environmental regulation on water pollution is still confronted with several dilemmas, for instance, the externalities triggered by "race to the bottom" of local governments, the spillover of water pollution governance and the uncertainty of water pollution control. By combing the mechanism of government environmental regulation, we found that the government environmental regulation still faces such major difficulties as the local government departmentalism is difficult to eliminate, the problem of information asymmetry and the regulatory capture are still not, iceable then puts forward that these plights can be effectively solved through implementing the river chief system, improving the social supervision of water pollution control.
\end{abstract}

\section{The current situation of water pollution}

In 2016, the ministry of land and resources carried out groundwater quality monitoring at 6124 monitoring sites (including 1,000 state-level monitoring sites)in 225 prefecture-level administrative regions in 31 provinces (autonomous regions and municipalities).The evaluation results showed that the monitoring points of water quality of ,excellent, good, medium, poor and very poor grade accounted for $10.1 \%, 25.4 \%, 4.4 \%, 45.4 \%, 14.7 \%$ and $60 \%$ of the groundwater quality in the monitoring range is poor, indicating that although the government has increased the policy and capital investment in the treatment of water pollution control in recent year, the academic research on it is also increasing, the situation of water pollution is still serious.

The basin is a region with strong spatial integrity and high correlation. In the basin, not only the natural elements are closely connected, but also the upper and middle and lower reaches and the dry tributaries are mutually constrained and mutually influential. Water is the source of life, polluting its easy, and the effective management of water pollution in the basins with large regional differences is like the difficulty of boarding the road. Compared with the intuitive air pollution, water pollution is more recessive. Pollution incidents, etc,seriously endanger the production and life of residents and bring great challenges to local government emergency work. The water pollution problem has the basic characteristics of pollution form diversity, interaction factor interaction, pollution degree dynamics, and the related complex problems induced by it, which poses a new challenge to river basin management.

\section{Literature review}

Environmental regulation, one of the government's environmental protection functions, is an important part of the government's social regulation. Environmental regulation refers to the behavior of state organs, industry associations and other entities to achieve environmental protection, apply specific environmental regulation tools, regulate the production and other behaviors of market entities, strengthen environmental pollution prevention and governance, and then achieve coordinated economic and environmental development. As environmental pollution problems become more prominent in China, more and more research has begun to pay attention to the government's role in environmental regulation for environmental protection.

In terms of government environmental regulation, there are related scholars to explore the causes of regulatory failures. For example, Yi Zhibin used the problem of transboundary water pollution as an example. He pointed out that local governments' regulation of environmental externalities is not always effective, that is, environmental regulation failures exist.Ma Yunze analyzed that the root causes of current environmental pollution problems in China are mainly the market failure characteristics of rational "economic man" assumptions, externalities and the nature of public goods, and the regulatory failure of environmental public management policies;Zang Chuanqin believes that under the condition of information asymmetry, the game between the government and the pollutant discharge enterprises reduces the effectiveness of government 
environmental regulation. It points out that the government should carry out regulatory policy innovation to encourage enterprises to disclose pollution information and improve regulation efficiency. Yu Guanghui and others proposed that in the process of environmental law enforcement in China, there was a problem of "regulatory capture" that was characterized by lax environmental law enforcement. He also believed that by regulating discretion and strengthening the responsibility system of environmental protection objectives, It can be cracked by introducing environmental citizen litigation in each environmental single-line law;According to the profit-seeking nature of enterprises and the consideration of political interests and economic interests by local government officials, Long Shuo and others discussed the mechanism of local environmental pollution caused by regulatory failure, and proposed that the central government should be supervised by the supervisory agency and the public. And the information asymmetry of the place to prevent collusion between government and enterprises. There are also related studies to discuss how to deal with regulatory failures, including An Zengjun and others to learn from the social regulation theory and incentive regulation theory to explore the local government's compensation mechanism for small watershed pollution treatment;Liu Xiliang etc.further explored how to innovate command-and-control, market-incentive and voluntary participation in environmental regulation tools to improve environmental pollution control.

The existing research explores the reasons for the government's environmental regulation, analyzes the performance and incentives of the government's regulatory failure, and provides more pertinent suggestions for improving the government's environmental regulation.However, there are also shortcomings, at present, the overall volume of the research on the combination of government environmental regulation and river basin water pollution control is not large.The necessity of environmental regulation and the analysis of its operational mechanism in watershed water pollution still need to be further improved B Based on this, this paper focuses on the necessity and operation mechanism of environmental regulation in watershed water pollution control, analyzes the incentive of water pollution regulation failure, and then puts forward some suggestions for strengthening government environmental regulation combined with the current regulatory tools, in order to provide decision-making reference for local governments to effectively carry out watershed water pollution regulation.

\section{Government regulation in river basin water pollution control}

\subsection{The necessity for the government to regulate water pollution in river}

According to the theory of regulatory economics, market failures are mainly manifested in externalities, public goods characteristics, and rational economic man assumptions. This is also the economic source of the current water pollution problems in the basin.

\subsubsection{Externalities caused by the "bottom-by-bottom competition"}

In recent years, the gradual economic decentralization and administrative decentralization between the central government and the local government in China have promoted the efficiency of the work of the local government, but also brought some negative effects.Coupled with the encouragement of the local leaders' political promotion vision, the benefit orientation of Local governments in many inland areas of China to seek economic development and promote the upgrading and transformation of local industries, to attract investment, limited by the difference of endowment.these areas should attract foreign investment to promote the development of local extensive economy, exhaust and fish, and bury the hidden dangers of water pollution in the basin.

\subsubsection{Spillover of water pollution in the river basin}

The water pollution in the basin has an area overflow effect, that is, the water quality of different administrative regions in the basin is interdependent, and the pollution discharge of the single administrative region can overflow to other adjacent areas.The contradiction between the entirety of the water pollution problem in the river basin and the division of the administrative division of the province (city), that is, the man-made administrative division and the organization of the administrative agency, destroyed the integration of the water environment of the river basin, leading to the "tragedy of commons" and the problem of water pollution.On the one hand, the water pollution control belongs to the quasi-public goods, has positive externality, and after the single local government pays the cost to treat the pollution, it is not possible to exclude the downstream area from the benefit range, and the problem of the ground-free car can be easily generated; on the other hand, the utility of the water pollution control of the river basin has the spillovers, Under the background of the lack of effective watershed ecological compensation system, some of the upstream local governments are unable to control the water pollution, and the downstream area is not willing to pay for the pollution discharge in the upstream area, which causes the water pollution problem of the river basin to become more serious.

\subsubsection{Uncertainty of watershed water pollution control}

Although for a long time, there has been a practical problem of "Kowloon water control" in the water pollution control of river basins in China. On the one hand, a single local government strict anti-pollution 
initial policies, resources and capital investment is larger, revenue cycle long and relatively hidden, is easy to cause a downturn of the economy in our region, difficult to achieve promotion achievement of this purpose, the results of the pollution treatment and want to share with downstream, so at present, river basin water pollution governance enforcement officials the fragmentation of the governance of solution to the status quo, hoping for more relying on authority; On the other hand, the cooperation mechanism among local governments at all levels are inadequate, to be constructed at a reasonable cost-sharing and benefit distribution mechanism to counteract conflicts between the individual sharing of pollution revenue, the social burden of pollution cost and the individual sharing of pollution control cost and the social share of pollution control revenue of upstream and downstream local governments. In addition, in the current water pollution control of the river basin, the power of the main body of social governance has not been fully utilized.

\subsection{The operating mechanism of government regulation of water pollution}

The reason for the government's environmental regulation is to consciously compensate for the market failure. Although the government is not necessarily an effective solvent for market failure, we still need to pay attention to how to make the government better environmental regulation before a more applicable strategy emerges. The path of government environmental regulation mainly includes the formulation of laws and regulations, the application of economic regulation methods and administrative regulations.

\subsubsection{The policies and regulations on water pollution prevention and control}

In order to effectively regulate water pollution problems in river basins and reduce the harm caused by water pollution, the Chinese government has successively formulated a series of laws and regulations since 1979 and introduced relevant policies, such as the"Environmental Protection Law of the People's Republic of China" in 2015. "The Water Law of the People's Republic of China "in 2016,"The law of the People's Republic of China on Water Pollution Prevention and Control"in 2018, and the "Interim Regulations on Water Pollution Prevention and Control of River Basins "formulated by the State Council or local governments for various river basins. After years of legal system construction and development, China's water pollution prevention policies and regulations have been completed day by day, and water pollution prevention and control work has gradually realized a transition from a small range of pollution passive management to a wide range of pollution prevention and control.

\subsubsection{Economic regulation means for prevention and control of water pollution}

Economic instruments often used in government environmental regulation include taxes and subsidies. The problem of water pollution can be largely attributed to the externalities generated by the pursuit of maximum profits. According to the relevant theories of welfare economics, the taxation of pollutants can internalize the external costs caused by the production activities of enterprises. The social cost caused by polluting the environment will also force some enterprises that cannot afford the cost to withdraw from the industry. The scene of "more pollution and more taxes, less pollution and less tax" will also help the company to carry out environmental protection technology innovation. In turn, the pollutant discharge unit will be gradually guided to reduce pollutant emissions and protect and improve the environment.

In terms of environmental protection subsidies, water pollution control is a quasi-public goods with positive externalities, which is in short supply. Through financial subsidies for the service providers, the production and supply of such products can be encouraged. Government subsidies for environmental protection take many forms, including tax breaks, such as government subsidies for research and development of technologies such as clean production and pollution purification.

\subsubsection{Administrative means of water pollution prevention and control}

The government's administrative measures for environmental regulation mainly include discharge permits, emission standards, and sewage charges. The pollutant discharge permit is a quantitative management method for the discharge of major pollutants in key areas and key pollution source units. By issuing a pollutant discharge permit to strictly control the discharge behavior of each pollutant discharge body in the water environment, the total discharge amount of key pollution sources can be effectively controlled.According to statistics, from the late 1980 s to the present, a total of 28 provinces (autonomous regions and municipalities) have issued local laws, regulations or regulatory documents related to sewage permit management. In 2018, the "Ministry of Environmental Protection issued the Measures for the Administration of Sewage Permits (Trial)", and the pollutant discharge permit entered the stage of comprehensive promotion. Wastewater discharge standards are mandatory technical indicators, and violation of this standard requires corresponding legal consequences.Since 1983, the Ministry of Environmental Protection has issued more than 60 water pollutant discharge standards for various industries. Sewage charges are mainly collected for units or individuals that cause environmental pollution, which plays a positive role in controlling water pollution and building ecological environment. China has established a sewage charge system in the Environmental Protection Law promulgated in 1979. According to statistics, from 2003 to 2015 , a total of 211,599 billion yuan was collected, 
and more than 5 million enterprises, public institutions and individual industrial and commercial households paid the pollutant discharge fee

\subsection{Difficulties in government environmental regulation}

Although the government's environmental regulation plays an important guiding role in environmental protection and economic and social sustainable development, the current environmental regulation still faces difficulties such as the difficulty of local government standardism, the problem of reverse information asymmetry and the significant risk of regulatory capture.

\subsubsection{Local government departmentalism cannot be eliminated}

The water pollution problem in the river basin is closely related to the central government's assessment mechanism for local officials. The political appeal of local officials is one of the causes of frequent environmental pollution accidents. Fiscal decentralization provides a strong incentive for local governments to develop their economies, but with economics.However, the single-dimensional incentives with the speed of economic development as the core have led to the distortion of local government motives. Local governments within the statutory scope, comprehensive resources to pursue the maximization of economic benefits is understandable, the speed of economic development not only affects the performance of local government work, but also affects the employment, income and social stability of residents, which deserves the attention of local leaders, but economic growth at the expense of the environment is not sustainable and should not be promoted.The localism of some local governments in the basin has aggravated the risk of collusion between government and enterprises, and relaxed the supervision of water pollution in the administrative region. The relevant entities showed active pollution discharge activities that dispersed negative externalities and passive pollution control options that expanded internality. Seriously hinder the effectiveness of regulation, affect the implementation of environmental regulations and the process of water pollution control in the basin.

\subsubsection{The problem of asymmetric reverse information is prominent}

Regulatory failure means that government actions cannot promote the improvement of the water environment in the basin. At present, the problem of information asymmetry in river basin water pollution control increases the cost of government-regulated corporate environmental behavior and exacerbates regulatory failure. On the one hand, the problem of information asymmetry between the central and local government is prominent, the central government occupies a dominant position and formulates policies and rules for water pollution control in the basin. As the executor of the central government pollution control policy, the local government can directly obtain data and information on water pollution. Under the premise of lack of incentive mechanism, local governments tend to perfuse and implement central water pollution control instructions for rational reasons, and pass false governance information to the central government to realize their own interests. The interaction between the central government's game position advantage and the local government's information advantage intensifies the complexity of the game. On the other hand, there is a problem of reverse information asymmetry between various local governments and sewage companies in the basin. For the sake of maximizing profits, enterprises have a tendency to conceal the true sewage situation in order to obtain more benefits, which makes it difficult for local governments to obtain enterprises at low cost. The actual information on sewage discharge, and due to the limitations of professional monitoring personnel and monitoring technical conditions, the degree of water pollution at the grassroots environmental monitoring station is easily distorted, coupled with the inevitable information distortion problem in the layer communication, the problem of reverse information asymmetry becomes more and more prominent.

\subsubsection{The capture risk of local government regulation is significant}

Administrative power is transferred from centralization to decentralization, which strengthens the function of local government and also makes local government the target of interest groups.Government capture refers to companies that influence the choice and formulation of laws, rules, and regulations by providing private compensation to government officials. By capturing government institutions, companies can transform their preferences into the basis of policy development in this area, creating institutional distortions that can realize their benefits, and at the same time causing high social costs.In terms of river basin water pollution, as long as the local government has the need to develop economy, regulation capture may occur, that is, it is easy for local government and enterprises to collude.For a long time, local governments at the grass-roots level lack strong supervision, coupled with the low salary of local government staff, using power for personal gain has become their main choice to meet their own interests, which also provides loopholes for some interest groups to capture regulations.As pollution intensive enterprise means the government capture appeared unceasingly, at the grass-roots level local governments increasingly easy to be polluted enterprises to obtain "pollution of the environment right" the economic costs and pay by "capture", as a result, not only induce administrative corruption, serious damage to the government image, also caused the high social costs, such as environmental pollution, directly affect the sustainable development of local economy and society. 


\section{The government's environmental regulation failure strategy}

The key to give full play to the effectiveness of government regulation in river basin water pollution control is to get rid of regulation capture and ensure the effectiveness of regulation. To this, one should strengthen the institutional constraints, in the process of law and policy to ensure that more public and extensive consultation, optimize economic decentralization incentive at the same time, improve the evaluation system of the government officials, to avoid the tendency of the local government to develop the economy at the expense of the environment, thus the scientific credibility of security system; Second, we need to strengthen law enforcement efforts to promote water environmental governance at all levels into an institutionalized and standardized track. Third, it is necessary to strengthen the supervision of the main body of river basin water pollution control, strengthen the supervision of the implementation of the government's environmental regulation, and prevent the local government from carrying out vicious competition to attract investment.

\section{1. system construction: comprehensively implementing the "the river chief system"}

"The River Chief System" " originated from the document "Wuxi River (Hu, Ku, Dang, Yi) Section Water Quality Control Targets and Assessment Measures (Trial)" issued by Wuxi City, Jiangsu Province in 2007 to address the problem of water pollution in the basin. In December 2016, the general office of the CPC central committee and the general office of the state council issued the "Opinions on Comprehensively Implementing The River Chief System" and issued a notice, urging all regions and departments to earnestly implement it in light of their actual conditions

Responsibility attribution of river basin water pollution problem is a key problem of multi-department coordination. The advantage of "the river chief system" lies in that it provides responsibility attribution of river basin water pollution problem from the system and solves the incentive problem of water pollution control.As a specific institutional arrangement for water environment management in the basin, the "the river chief system" in the sense of the current system refers to the "river chief" of the rivers (lakes, reservoirs, etc.) under the jurisdiction of the party and government at all levels. On the one hand, the "the river chief system" can realize the resource integration of water pollution control in the river basin to a certain extent. Most of the "river chief" is the main person in charge of the local party and government cadres, and can integrate the resources of relevant functional departments in water pollution control. Coordinating conflicts of interest between the central government, local governments, and different departments to achieve more efficient water pollution control; on the other hand, the "the river chief system" helps reduce the risk of linkages between power and interests in government regulation. Under the law, the salary and promotion of "river chief" is linked to the effectiveness of water pollution control in the river basin. Therefore, the government' $\mathrm{s}$ water environment regulation is more effective and it is more likely to have governance results.

\subsection{Law enforcement: the guarantee mechanism for the implementation of policies and regulations}

The consequences of government regulation and capture are mainly reflected in the design and implementation aspects of the regulation policy. In the formulation of laws and regulations on water pollution prevention and control, since the promulgation of the "Environmental Protection Law (Implementation)" in 1979, China has successively issued and implemented nearly 30 The law of environmental protection and pollution prevention, and with the continuous improvement of water pollution prevention and control laws and regulations, the water pollution situation is still relatively severe..The river basin water environment management system should aim at water pollution prevention and control, gradually improve the organization and law enforcement team that adapt to the characteristics and actual needs of water pollution control, and promote the water pollution prevention and control of each level of the basin to enter an institutionalized and standardized track. In this regard, the first is to focus on cultivating the "public spirit" of local governments, strengthening the education of local government leaders, establishing a comprehensive concept of sustainable economic and social development, and improving the efficiency of water pollution control policies; Gradually increase the monitoring level of grassroots water pollution, build a professional team of water pollution monitoring personnel, and apply professional monitoring equipment to grasp the pollution trends and changes in the water environment of the river basin, and take necessary preventive measures in time to further reduce the risk of sudden water pollution incidents. The third is to increase the law enforcement of water pollution control and water environmental protection in the basin, investigate and deal with illegal activities that pollute and destroy the water environment in the basin, and establish a legal awareness of water environment protection in the basin.

\subsection{Complete supervision: strengthen the supervision of government regulation}

The level of water pollution control in river basins can be measured by the improvement of pollution control capacity and the reduction of pollution control costs. The cost of pollution control includes management costs, technical costs, supervision costs, and Opportunity cost of policy inefficiency. Strengthening the supervision of government environmental regulation and the social supervision of water pollution control can effectively reduce the cost of government management and the central government's supervision of local governments, 
and reduce the risk of local government and enterprise collusion.Specifically, the first is to enrich the main body of supervision and take measures to exert the supervisory role of the media, environmental protection organizations, the public, enterprises and other subjects in various stages and levels of water pollution control in the basin. The regional environmental protection social organization will guide the relevant entities to reach a voluntary agreement on water conservation in the river basin, cultivate local residents to participate in the social atmosphere of water environmental protection, and cultivate the social responsibility of enterprises in the prevention and control of water pollution through public recognition and other forms of honorary incentives; The second is to standardize the way of supervision, through the formulation of laws and regulations and the introduction of policies, clear the regulatory measures for local government environmental regulation, strengthen the assessment and implementation of local government water environmental protection, give the supervision method a statutory status, and reduce the improper supervision The risk of failure of environmental protection policies; the third is the smooth supervision channels. The basis for the orderly participation of social subjects in water pollution control is to construct appropriate channels of participation, and to unblock the channels of supervision, including network reporting and complaints, to protect the residents of the basin. Participation and expression rights play an important role in promoting the process of social democratization. Fourth, the application of supervision results. The focus of foreign body supervision is on the use of supervision results. Whether the actual results of supervision can be used to spur or praise the governance subject is the effectiveness of supervision.

\section{The conclusion}

Over the past 30 years, the environmental protection legal system has overlapped with the government's environmental regulations, making water pollution control continue to achieve results. Despite this, the current problem of water pollution in China's river basins is still severe, coupled with the hidden characteristics of air pollution and solid waste pollution, which poses a large environmental emergency risk. By describing the current status of water pollution in the basin, we have sorted out the necessity of the government's water environmental regulation and its regulatory mechanism, and also pointed out the main dilemma faced by the government's environmental regulation, and accordingly proposed a comprehensive system that can pass the "the river chief system". It can be broken through the comprehensive implementation of the "the river chief system", strengthening the enforcement of environmental regulations and the social supervision of water pollution control.

The ecological and social complexity of watershed water pollution problems determines that it takes a long period of time to achieve effective governance.At a time when the water pollution situation is more severe, the social concern is high, and the water pollution prevention policies and regulations are becoming more comprehensive,strengthening watershed water environment management and building a long-term water pollution prevention and control system is important for giving full play to the local government's environmental functions, improving the government's environmental regulation effectiveness, maintaining a good government image, and promoting local economic and social sustainable development.

\section{Authors}

${ }^{1}$ Chu Yijing, PhD, associate professor, Wuhan Technical College of Communications, Economic Management cademy, E-mail: xiaojing618@126.com

${ }^{2}$ Corresponding Author: Wang Jue, master, lecturer, Wuhan Technical College of Communications, Economic Management cademy. E-mail: bestywang@qq.com

\section{Fund Project:}

The annual project of national social science fund: Mechanism Research of "Co-construction -Co-governance -- Sharing" of Trans-regional Ecological Environment in the Yangtze River Economic Belt." (16BGL200);

Key project of national social science fund: "Research on Integrated and Integrated Governance Model of Cross-domain Ecological Environment”'(18AZD004)

\section{Reference}

1. An Zengjun, Liu Jun.(2011)Incentives to the government and incentives to the regulated in social regulation-based on compensation for small watershed pollution treatment in local administrative jurisdictions [J]. Southeast Academic, (3).

2. Long Shuo, Hu Jun.(2014)Environmental pollution from the perspective of government and enterprise collusion: theoretical and empirical research [J]. Financial Research, 40 (10).

3. Liang Pinghan, Gao Nan.(2014)Personnel change, legal environment and local environmental pollution [J]. Management World, (6).

4. Ren Min.(2015)"the river chief system":a sample study of cross-sectoral collaboration in watershed management of the Chinese government [J]. Journal of Beijing university of administration ,(3).

5. Wu Ruiming etc.(2013) Analysis of evolutionary game stability in river basin pollution control [J]. Journal of Systems Management, 22(6).

6. Ye Hongqing, Song Yihong.(2014)Environmental pollution, government regulation and competition for investment [J]. Asia-Pacific Economy, (3).

7. Zheng Siqi.(2013)Public appeals and urban environmental governance [J]. Management World, (3). 
8. Zhang Wei, Liu Minglian.(2017)Based on the prospect theory, water pollution control government and enterprise collusion supervision [J]. Systems Engineering, (2). 